\title{
Növényevő darazsak a Látrányi Puszta Természetvédelmi Területről (Hymenoptera: Symphyta)
}

\author{
HaRIS ATTILA
}

Hungarian National History Museum, H-1088 Budapest, Baross u. 13., Hungary

\section{HARIS A.: Sawflies from the Látrányi Puszta Nature Conservation Area (Hymenoptera: Symphyta)}

Abstract: 87 Symphyta species collected from Látrányi Puszta Nature Conservation Area. Rare species: Dolerus quadrinotatus Bíró,1884; Dolerus nigrominutus Haris, 1998; Stethomostus funereus (Klug, 1814); Hoplocampa chrysorrhoea (Klug, 1814) ; Nematus flavescens Stephens, 1853.

Key words: Symphyta, rare species, nature conservation, Hungary

\section{Bevezetés}

A Látrányi Puszta Természetvédelmi Terület 1992-től országosan védett státust kapott. A terület kis kiterjedése ellenére gazdag és értékes faunával rendelkezik, amelynek az alapja a változatos vegetáció. A növényzet túlnyomó részét, 160 ha-t, gyep alkotja. Ezen belül megtalálhatók a száraz rétek: homoki sztyepprét, de az igen fajgazdag faunát eltartó nedves rétek is, mint a szittyós láprét, a zsombéksásos, a télisásos, mocsári sásos, a pántlikafüves, vagy a sédbúzás mocsárrét. A kúpvirág-aranyvesszö társulás, a rozsnokos akácos jelzi a terület részlegesen degradált állapotát.

A 223 hektáros összterületen 37 hektár erdő található, jellegzetes fafajai a tölgy és az éger.

\section{Anyag és módszer}

1999-2000 tavaszain rendszeresen végeztünk gyűjtőmunkát a terepen. Gyüjtők: Dr. Ábrahám Levente, Dr. Haris Attila, Rozner György, Józan Zsolt. Alkalmazott gyüjtési módszerek: fühálózás, lombhálózás, kopogtatóernyőzés. A határozáshoz ZoMBORI et MóczÁr (1973), Zombori (1973, 1990), ZHELOCHOVTSEV (1988) És HARIS (1998) munkáit használtam fel.

\section{Eredmények}

1999-2000 folyamán számos terepnapot töltöttünk a Látrányi Puszta Természetvédelmi Területen. A következőkben összefoglaljuk az eredményeket, megadjuk a gyüjtött fajok jegyzékét, tápnövényeiket, kiemelten foglalkozunk a ritka fajokkal 
és a veszélyeztető tényezőkkel. 87 faj 292 példányát gyüjtöttük be. Jellegzetes, gyakori fajok: Dolerus vestigialis (Klug, 1818); Atomostethus ephippium (Panzer, 1798); Eutomostethus luteiventris (Klug, 1816); Aglaostigma aucupariae (Klug, 1817); Aglaostigma fulvipes (Scopoli, 1763); Macrophya albicincta (Schrank, 1776); Macrophya duodecimpunctata (Linné, 1758).

\section{Ritka fajok}

Dolerus quadrinotatus Bíró, 1884

Igen ritka faj. Magyarország területéről eddig mindössze néhány példányban ismert a következő helyekröl: Borosjenö, Németbogsán, Szöllöske, Tasnád és Simontornya. A faj hazánkon kívül Sapnyolországból is ismert.

Dolerus nigrominutus Haris, 1998

A szerző által nemrégiben leírt faj látrányi előfordulása igen meglepö. A típussorozat lelöhelyein kívül: Budakeszi, Budapest, Rákospalota, egy példány ismert még Szécsényből. Valamennyi példány hím, a nöstény ismeretlen, feltehetőleg csökevényes szárnyú. A Látrányban gyüjtött hímmel a faj ismert példányainak száma 14.

Stethomostus funereus (Klug, 1814)

Hazánkból eddig egy hímet, Tákos: Bockereki-erdő és egy nőstényt ismertünk a barcsi Ösborókás területéröl, Darányból. A Látrányban gyüjtütt nőstény a harmadik hazai példány.

Hoplocampa chrysorrhoea (Klug, 1814)

Magyarország területéröl eddig 1-1 példánya került elő a következö lelőhelyekről: Budaörs, Csákvár, Lebujpuszta és Borosjenő. Látrányból 3 nőstény példány került elö.

Nematus flavescens Stephens, 1835

Magyarországon ritka. Egy nőstény példányt ismerünk Soroksárról 1920-ból és egy ugyancsak nőstény példányt Pestről 1882-böl (HARIS 2001).

\section{Természetvédelmi megjegyzések}

A terület egy jelentős részét telepitett fenyves (erdei fenyő ) foglalja el. A faj idegen flóraelem, nem tájba illő. Kivágása és a flórába illeszkedő más fafajokkal való helyettesítése kívánatos lenne.

A legeltetés természetvédelmi hatását meg kell vizsgálni. Hogyan hat az eredeti vegetációra, mennyiben veszélyezteti a terület flóráját, illetve ha szükséges a fenntartása, úgy mennyire fontos a gyomosodás elkerülése érdekében?

\section{A gyüjtött fajok jegyzéke}

Rövidítćsck: f: nőstćny, m: hím

Pamphilidae

Pamphilius sylvaticus (Linné, 1758): 13. 05. 2000, $2 \mathrm{~m}$.

Pamphilius vafer (Linnć, 1767): 30. 04. 1999, 1 f.

\section{Megalodontidae}

Megalodontes plagiocephalus (Fabricius, 1804):

13. 05. 2000, 2 m.; 19. 05. 1999, $1 \mathrm{~m}$.

\section{Cephidae}

Calameuta pallipes (Klug, 1803): 28. 04. 2000, $2 \mathrm{f}$. Calameuta punctata (Klug, 1803): 13. 05. 2000, $1 \mathrm{~m}$. Cephus brachycerus C. G. Thomson, 1871: 28.
Cephus cultratus Eversmann, 1847: 13. 05. 2000, 2 f.

Cephus nigrinus C. G. Thomson, 1871: 13. 05. 2000, $2 \mathrm{f}$.

\section{Argidae}

Arge cyanocroeca (Förster, 1871): 09. 06. 1999,

$1 \mathrm{f} ;$; 16. 06. 1991, $1 \mathrm{~m}$. Arge enodis (Linné, 1767): 09. 06. 1999, 1 f., 30.

07. 1991, $1 \mathrm{f}$. Arge ochropus (Gmelin, 1790): 09. 06. 1999, $1 \mathrm{f}$.

\section{Cimbicidae} Abia sericea (Linné, 1767): 20. 04. 2000, 1 f.

04. $2000,1 \mathrm{f}$ 


\section{Tenthredinidae}

\section{Allantinae} Allantus melanarius (Klug, 1818): 28. 04. 2000,

1. f.; $13.05 .2000,1 \mathrm{~m}$. Ametastegia equiseti (Fallén, 1808): 20. 04. $2000,1 \mathrm{f}$. Ametastegia tener (Fallén, 1808): 14. 04. 2000, 1 m.; 20. 04. 2000, $1 \mathrm{f}$. Athalia cordata Lepeletier, 1823: 13. 05. 2000, 2 f. ; 13. 04. $2001,1 \mathrm{~m}$. ; 26. 04. 2001, 1 f. ; 16. 05. $2001,1 \mathrm{f}$. Athalia rosae (Linné, 1758): 05. 10. 2001, $3 \mathrm{f}$. Caliroa varipes (Klug, 1816): 30. 04. 1999, 1 m.;

28. 04. 2000, $1 \mathrm{~m}$. Empria klugii (Stephens, 1835): 03. 04. 1999, 1 f.; 20. 04. $2000,1 \mathrm{f}$. Empria liturata (Gmelin, 1790): 14. 04. 2000, 1 m.; 15. 04. 1999, 1 f. ; 28. 04. 2000, 1 f. Empria parvula (Konow, 1891): 20. 04. 2000, $1 \mathrm{f}$. f., $1 \mathrm{~m}$. Empria tridens (Konow, 1896): 14. 04. 2000, 1 Eriocampa ovata (Linné, 1761): 13. 05. 2000, 1 f. ; 30. 05. 1999, $1 \mathrm{f}$. Monostegia abdominalis (Fabricius, 1798): 13. 05. $2000,1 \mathrm{f}$. Monsoma pulveratum (Retzius, 1783): 14. 04. $2000,1 \mathrm{f}$.

\section{Selandrinae}

Nesoselandria morio (Fabricius, 1781): 13. 05. 2000, 2 f., 1 m. ; 28. 04. 2000, 2 m.

Selandria serva (Fabricius, 1793): 30. 04. 1999, $1 \mathrm{f} ;$; 28. 04. 2000, $4 \mathrm{f}$.

\section{Dolerinae}

Dolerus asper Zaddach, 1859: 28. 04. 2000, 1 f.; 20. 04. 2000, 2 f; 14. $04.2000,1$ f.

Dolerus bimaculatus (Geoffroy, 1785): 20. 04. 2000, $1 \mathrm{~m}$.

Dolerus germanicus (Fabricius, 1775): 13. 05. 2000, 1 f., 2 m.; 29. 04. 2000, 3 f.

Dolerus nigratus (O. F. Müller, 1776): 20. 04. 2000, 2 f, 14. 04. 2000, 1 f., 31. 03. 2000, 2 f.

Dolerus nigrominutus Haris, 1998: 31. 03. 1999, $1 \mathrm{~m}$.

Dolerus picipes (Klug, 1818): 14. 04. 2000, 1 f.; 30. 04. 1999, 1 f., 3 m.; 28. 04. 2000, 1 f., 29.04. $2000,1 \mathrm{f}$.

Dolerus puncticollis Thomson, 1871: 14. 03. 2002, $1 \mathrm{f}$. $1 \mathrm{f}$.

Dolerus quadrinotatus Bíró, 1884: 14. 04. 2000,

Dolerus vestigialis (Klug, 1818): 30. 04. 1999, 1 m., 1 f.; 15. 04. 1999, 2 m., 1 f.; 20. 04. 2000, 4 m.; 28. 04. $2000,3 \mathrm{~m}$; 13. 05. 2000, 1 f. ; 13. 04. 2001, $1 \mathrm{~m}$.

\section{Blennocampinae}

Atomostethus ephippium (Panzer, 1798): 20. 04. 2000, 1 f., 5 m.; 28. 04. 2000, 1 f., 5 m.; 13. 05. 2000, $1 \mathrm{~m}$.

Claremontia alternipes (Klug, 1816): 14. 04. 2000, $1 \mathrm{~m}$.

Eutomostethus luteiventris (Klug, 1816): 20.04. 2000, 3 f.; 28. 04. 2000, 3 f.; 29. 04. 2000, 1 m.; 13. $05.2000,8 \mathrm{f}$.

Halidamia affinis (Fallén, 1807): 30. 05. 1999, 1 f.; $28.04 .2000,1 \mathrm{f}$.

Monophadnus pallescens (Gmelin, 1790): 14. 04. 2000, 1 f. ; 26. 04. 2002, 2 f.

Periclista albiventris (Klug, 1816): 30. 05. 1999, $1 \mathrm{f}$.

Stethomostus fuliginosus (Schrank, 1781): 30. 05. 1999, 1 f.; 20. 04. 2000, 3 f., 1 m.; 29. 04. 2000 , $1 \mathrm{~m}$.

Stethomostus funereus (Klug, 1816): 20. 04. $2000,1 \mathrm{f}$.

Monophadnoides rubi (Harris, 1845): 14. 04. $2000,1 \mathrm{~m}$.

\section{Tenthredininae}

Aglaostigma aucupariae (Klug, 1817): 30.04. 19899, 1 m.; 28. 04. 2000, 3 f., 1 m.; 20. 04. 2000, 3 f. ; 14. 04. $2000,1 \mathrm{f}$.

Aglaostigma fulvipes (Scopoli, 1763): 28. 04. 2000, 2 f., 8 m.; 15. 04. 1999, 1 m.; 13. 05. 2000, 1 f.; 30. 04. 1999, $1 \mathrm{~m}$.

Macrophya albicincta (Schrank, 1776): 30. 05. 1999, 9 f.; 20. 04. 2000, 5 m., 3 f.; 15. 04. 1999, 1 f., 1 m.; 14. 04. 2000, 2 f., 4 m. ; 26. 04. 2002, 1 f.; 16. $05.2001,1 \mathrm{~m}$.

Macrophya annulata (Geoffroy, 1785): 13. 05. 2000, 6 m.; 30. 05. 1999, 1 f.

Macrophya duodecimpunctata (Linné, 1758):

13. 05. 2000, 1 f., 14 m.; 28. 04. 2000, 8 f., 8 m.; 30 .

05. 1999, $1 \mathrm{~m}$.

Macrophya punctum-album (Linné, 1767): 13.

05. 2000, 1 f., $1 \mathrm{~m}$.

Macrophya rufipes (Linné, 1758): 28. 04. 2000, $1 \mathrm{~m}$. Macrophya sanguinolenta (Gmelin, 1790): 30. 05. 1999, 1 f.

Pachyprotasis rapae (Linné, 1767): 14. 04. 2000, 1 f.; 13. 05. 2000, 1 f.

Rhogogaster viridis (Linné, 1758): 13. 05. 2000, 1 f., 2 m.; 30. 05. 1999, 1 f.

Sciapteryx consobrina (Klug, 1816): 14. 04. $2000,1 \mathrm{~m}$

Sciapteryx costalis (Fabricius, 1775): 14. 04. $2000,1 \mathrm{~m}$.

Tenthredo excellens (Konow, 1886): 13. 05. 2000, $1 \mathrm{f}$.

Tenthredo maculata Geoffroy, 1785: 30. 04. 1999, $1 \mathrm{f}$.

Tenthredo mesomelas Linnacus, 1758: 13. 05. $2000,1 \mathrm{f}, 1 \mathrm{~m}$ 
Tenthredo omissa (Förster, 1844): 20. 06. 1999, 1 f. Tenthredo temula Scopoli, 1763: 13. 05. 2000, 1

f., $1 \mathrm{~m}$.

Tenthredo zonula Klug, 1817: 13. 05. 2000, $1 \mathrm{~m}$; 16. 06. $1991,1 \mathrm{~m}$.

Tenthredopsis austriaca Konow, 1890: 30. 05. 1999, $1 \mathrm{f}$.

Tenthredopsis lactiflua (Klug, 1817): 20, 04. 2000, 1 m.; 28. 04. 2000, $1 \mathrm{~m}$.

Tenthredopsis litterata (Geoffroy, 1785): 13. 05. $2000,1 \mathrm{~m}$.

Tenthredopsis nassata (Linné, 1767): 13. 05. 2000, I f.; 28. 04. 2000, 1 f.

Tenthredopsis pavida (Fabricius, 1775): 30. 05. 1999, $1 \mathrm{~m}$.

Tenthredopsis scutellaris (Fabricius, 1804): 13. 05. $2000,1 \mathrm{~m}$.

Tenthredopsis sordida (Klug, 1817): 13. 05 $2000,1 \mathrm{f}$.

Tenthredopsis excisa (Thomson, 1870): 28. 04. 2000,3 f.; 13. 05. 2000, $4 \mathrm{f}$

\section{Nematinae}

Amauronematus lateralis Konow, 1896: 30. 04. 1999, 1 f.

Amauronematus viduatus (Zetterstedt, 1838): 31.

03. $1999,1 \mathrm{f}$

\section{A gyüjtött fajok tápnövényei (LISTON 1995)}

Adoxa (pézsmaboglárka)

Sciapteryx consobrina (Klug, 1816)

Agrimonia (párlófü)

Macrophya rufipes (Linné, 1758)

Ajuga (ínfü)

Athalia cordata Lepcletier, 1823

Alnus (éger)

Pamphilius vafer (Linné, 1767); Eriocampa ovata (Linné, 1761); Monsoma pulveratum (Retzius, 1783); Rhogogaster viridis (Linné, 1758); Nematinus luteus (Panzer, 1805); Nematus viridissimus Möller, 1882; Platycampus luridiventris (Fallén, 1808)

\section{Anagallis (tikszem)}

Monostegia abdominalis (Fabricius, 1798)

Anemone (szellörózsa)

Sciapteryx consobrina (Klug, 1816)

Anterrhinum

Athalia cordata Lepeleticr, 1823

Anthriscus (turbolya)

Tenthredopsis nassata (Linné, 1767)
Hoplocampa chrysorrhoea (Klug, 1816): 20.04. 2000, 3 f.

Mesoneura opaca (Klug, 1819): 23. 04. 2002, 1 f. Nematinus luteus (Panzer, 1805): 30. 04. 1999, $1 \mathrm{f}$. Nematus flavescens Stephens, 1853: 11. 07.

2001, 1 f.

Nematus myosotidis (Fabricius, 1804): 28. 04. 2000, 1 f.; 20. 04. 2000, 1 f.

Nematus viridissimus Möller, 1882: 28. 04. $2000,1 \mathrm{f}$

Pachynematus clitellatus (Serville, 1823): 20 04. $2000,1 \mathrm{f}$.

Phyllocolpa leucaspis (Tischbein, 1846): 30. 04. 1999, 1 f., 3m.; 28. 04. 2000, 2 f.

Phyllocolpa leucosticta (Hartig, 1837): 30.04. 1999, 2 f.; 28. 04. 2000, 2 f., 1 m.

Platycampus luridiventris (Fallén, 1808): 30.05. 1999, $1 \mathrm{f}$.

Priophorus morio (Lepeletier, 1823): 30. 04. 1999, 1 f.

Pristiphora aquilegiae (Vollenhoven, 1866): 28. 04. $2000,1 \mathrm{~m}$.

Pristiphora bifida Hellén, 1947: 13. 05. 2000, 1 f. Pseudodineura fuscula (Klug, 1816): 26. 04. 2002, $1 \mathrm{f}$.

Artemisia (üröm)

Tenthredopsis nassata (Linnć, 1767)

Betula (nyír)

Caliroa varipes (Klug, 1816)

\section{Carex (sás)}

Dolerus asper Zaddach, 1859; Macrophya duodecimpunctata (Linné, 1758); Tenthredopsis nassata (Linné, 1767); Tenthredopsis sordida (Klug, 1817); Pachynematus clitellatus (Serville, 1823)

\section{Chamnaerion}

Rhogogaster viridis (Linné, 1758)

\section{Chenopodium (libatop)}

Ametastegia equiseti (Fallén, 1808)

\section{Circaea (varázslófü)}

Rhogogaster viridis (Linné, 1758)

Cirsium (aszat)

Ametastegia tener (Fallén, 1808)

Cornus (som)

Allantus melanarius (Klug, 1818)

\section{Craetegus (galagonya)}

Pamphilius sylvaticus (Linné, 1758) 
Cruciferae (keresztesvirágúak)

Athalia rosae (Linné, 1758)

\section{Cyperaceae (sásfélék)}

Selandria serva (Fabricius, 1793); Macrophya duodecimpunctata (Linné, 1758); Tenthredopsis pavida (Fabricius, 1775)

\section{Equisetum (zsurló)}

Dolerus bimaculatus (Geoffroy, 1785); Dolerus germanicus (Fabricius, 1775); Dolerus vestigialis (Klug, 1818)

\section{Filipendula (legyezőfü)}

Ametastegia tener (Fallén, 1808); Monophadnoides rubi (Harris, 1845); Rhogogaster viridis (Linné, 1758)

\section{Fragaria (szamóca)} Abia sericea (Linné, 1767); Empria liturata (Gmclin, 1790)

\section{Fraxinus (kőris)}

Macrophya punctum-album (Linné, 1767)

Galeopsis Macrophya sanguinolenta (Gmelin, 1790)

\section{Gallium (galaj)}

Halidamia affinis (Fallén, 1807); Aglaostigma aucupariae (Klug, 1817); Aglaostigma fulvipes (Scopoli, 1763)

\section{Geum (gyömbérgyökér)}

Empria klugii (Stephens, 1835); Empria liturata (Gmclin, 1790); Empria tridens (Konow, 1896); Monophadnoides rubi (Harris, 1845).

\section{Glaux (bagolyfü)} Monostegia abdominalis (Fabricius, 1798).

Hypericum (orbáncfü) Tenthredo zonula Klug, 1817.

Juncus (szittyó) Eutomostethus luteiventris (Klug, 1816); Pachynematus clitellatus (Serville, 1823).

\section{Knautia (varfü)} Abia sericea (Linné, 1767).

\section{Ligustrum (fagyal)} Macrophya punctum-album (Linné, 1767); Tenthredo temula Scopoli, 1763.

\section{Lysimachia (lizinka)} Monostegia abdominalis (Fabricius, 1798).

Onobrychis (baltacim) Nematts myosotidis (Fabricius, 1804).
Origanum (majorána, szurokfü) Tenthredo temula Scopoli, 1763.

\section{Peucedanum (kocsord)} Megalodontes plagiocephalus (Fabricius, 1804).

\section{Plantago (útifü)}

Ametastegia equiseti (Fallén, 1808); Athalia cordata Lepeletier, 1823; Tenthredo omissa (Förster, 1844).

\section{Poaceae (fü)}

Cephus cultratus Eversmann, 1847; Cephus nigrinus C. G. Thomson; Selandria serva (Fabricius, 1793); Dolerus asper Zaddach, 1859; Dolerus nigratus (O. F. Müller, 1776); Dolerus picipes (Klug, 1818); Atomostethus ephippium (Panzer, 1798); Macrophya duodecimpunctata (Linné, 1758); Tenthredo maculata Geoffroy, 1785; Tenthredopsis litterata (Geoffroy, 1785); Tenthredopsis nassata (Linné, 1767); Tenthredopsis scutellaris (Fabricius, 1804); Tenthredopsis sordida (Klug, 1817); Tenthredopsis excisa (Thomson, 1870); Tenthredopsis pavida (Fabricius, 1775); Pachynematus clitellatus (Serville, 1823); Dolerus puncticollis Thomson, 1871.

\section{Polygonum (keserüfü)}

Ametastegia equiseti (Fallén, 1808).

Populus (nyár)

Rhogogaster viridis (Linné, 1758).

Potentilla (pimpó)

Macrophya annulata (Gcoffroy, 1785).

\section{Prunus (kökény)}

Pamphilius sylvaticus (Linné, 1758); Hoplocampa chrysorrhoea (Klug, 1816).

Quercus (tölgy)

Caliroa varipes (Klug, 1816); Mesoneura opaca (Klug, 1819).

\section{Ranunculus (boglárka)}

Monophadnus pallescens (Gmelin, 1790); Stethomostus fuliginosus (Schrank, 1781); Sciapteryx consobrina (Klug, 1816); Sciapteryx costalis (Fabricius, 1775); Pseudodineura fuscula (Klug, 1816).

\section{Rosa (vadrózsa)}

Arge ochropus (Gmelin, 1790).

\section{Rubus (szeder)}

Arge cyanocroeca (Förster, 1871); Empria tridens (Konow, 1896); Claremontia alternipes (Klug, 1816); Monophadnoides rubi (Harris, 1845); Priophorus morio (Lepeletier, 1823). 


\section{Rumex (sóska) \\ Ametastegia equiseti (Fallén, 1808); Ametastegia tener (Fallén, 1808) \\ Salix (füz) \\ Arge enodis (Linné, 1767); Caliroa varipes (Klug, 1816); Monsoma pulveratum (Retzius, 1783); Rhogogaster viridis (Linné, 1758); Amauronematus lateralis Konow, 1896; Amauronematus viduatus (Zcttcrstedt, 1838); Phyllocolpa leucaspis (Tischbcin, 1846); Phyllocolpa leucosticta (Hartig, 1837); Pristiphora bifida Hellén, 1947; Nematus flavescens Stephens, 1853}

\section{Sambucus (bodza)}

Macrophya albicincta (Schrank, 1776)

Senecio (aggófü)

Macrophya sanguinolenta (Gmelin, 1790)

Sorbus (berkenye)

Pamphilius sylvaticus (Linné, 1758)

Stellaria (csillaghúr, tyúkhúr)

Rhogogaster viridis (Linné, 1758)

\section{Succisia (ördögharaptafü)}

Abia sericea (Linné, 1767)
Trifolium (here)

Nematus myosotidis (Fabricius, 1804)

Valeriana (macskagyökér)

Macrophya albicincta (Schrank, 1776)

\section{Veronica}

Macrophya sanguinolenta (Gmelin, 1790)

\section{Viburnum (bangita)}

Macrophya albicincta (Schrank, 1776)

\section{Vitis (szölö)}

Macrophya rufipes (Linné, 1758)

\section{Polifág}

Pachyprotasis rapae (Linné, 1767); Tenthredo mesomelas Linnaeus, 1758

\section{Tápnövénye ismeretlen}

Calameuta pallipes (Klug, 1803); Calameuta punctata (Klug, 1803); Cephus brachycerus C. G. Thomson, 1871; Nesoselandria morio (Fabricius, 1781); Dolerus nigrominutus Haris, 1998; Dolerus quadrinotatus Bíró, 1884; Empria parvula (Konow, 1891); Periclista albiventris (Klug, 1816); Stethomostus funereus (Klug, 1816); Tenthredo excellens (Konow, 1886); Tenthredopsis lactiflua (Klug, 1817); Tenthredopsis austriaca Konow, 1890

\section{Irodalom}

HARIS A. 1998: Two new Dolerus species (Hymenoptera: Tenthredinidae). Folia Entomologica Hungarica. 59: 131-134.

HARIS A. (2001) Revisional list of the Hungarian Nematinae with the description of three new species (Hymenoptera: Tenthredinidae). Folia Entomologica Hungarica 62 95-114.

Liston, A. D. (1995) Compendium of European Sawflies. Chalastos Forestry, Gottfrieding. 1-190.

MóczÁr L. ET ZOMBORı L. 1973: Levéldarázs-alkatúak I. - Tenthredinoidea 1. Fauna Hungariae 111. Akadémiai Kiadó, Budapest. pp. 1-128.

ZHELOCHOVTSEV, A. N. 1988: Opredelitel nasckomych cvropejskij tschasti SSSR. 3(6) Nauka, Leningrad. pp.1-234.

Zomborı L. 1982: Levéldarázs-alkatúak Il. - Tenthredinoidea II. Fauna Hungariac 153. Akadémiai Kiadó, Budapest. pp. 1-144.

ZOMBORI L. 1990: Levéldarázs-alkatúak III. - Tenthredinoidea III. Fauna Hungariac 165. Akadémiai Kiadó, Budapest. $81 \mathrm{pp}$ 


\section{Sawflies from the Látrányi Puszta Nature Conservation Area \\ (Hymenoptera: Symphyta)}

\section{ATTILA HARIS}

292 specimens of 87 Symphyta species were collected in the Látrányi puszta Nature Conservation Area.

Collectors: Dr. Levente Ábrahám, Dr. Attila Haris, György Rozner, and Zsolt Józan.

Identified by: Dr. Attila Haris.

Rare species:

Dolerus quadrinotatus Bíró,1884 - We know it only from Borosjenő, Németbogsán, Szöllöske, Tasnád and Simontornya. It is also collected from Spain.

Dolerus nigrominutus Haris, 1998 - The newly described species is collected from Budakeszi, Budapest, Rákospalota and Szécsény. The occurrence in Látrány is surprising. We know only the males. The species is very similar to Dolerus picipes (Klug, 1818) but the penis valve clearly separate this species. The female is possibly wingless.

Stethomostus funereus (Klug, 1814) - Known only from Tákos: Bockereki-erdö (1 male) and from Darány (1 female).

Hoplocampa chrysorrhoea (Klug, 1814) - 2 females are captured in Látrány. Known also from Budaörs, Csákvár, Lebujpuszta and Borosjenő.

Nematus flavescens Stephens, 1853 - Rare in Hungary. 1 female collected in Pest in 1920 and 1 other in Soroksár in 1882.

Dominant species are: Dolerus vestigialis (Klug, 1818); Atomostethus ephippium (Panzer, 1798); Eutomostethus luteiventris (Klug, 1816); Aglaostigma aucupariae (Klug, 1817); Aglaostigma fulvipes (Scopoli, 1763); Macrophya albicincta (Schrank, 1776); Macrophya duodecimpunctata (Linné, 1758).

Endangering factors of the landscape: Pinus silvestris plantation (not inhabitant pine species in the territory). The possible damaging effect of the animal breeding. 